\title{
Barriers to Participation in Vocational Orientation Programmes Among Prisoners
}

\author{
DORIEN BROSENS, LIEBETH DE DONDER, SARAH DURY \& DOMINIQUE VERTÉ \\ Vrije Universiteit Brussel
}

\begin{abstract}
This study investigates the barriers to prisoners' participation in vocational orientation programmes, as well as the predictors of different types of barriers. Survey data derived from a project in a remand prison in Belgium $(N=468)$ provided the empirical evidence for the analyses. The results indicate that facing situational and informational barriers are most common. Based on the different kinds of barriers, various types of non-participants can be distinguished and multinomial logistic regression analyses are conducted to identify in what way participants of vocational orientation programmes differ from various types of non-participants. For instance, prisoners with a poor understanding of the Dutch language and those who never/rarely receive visitors participate less in vocational orientation programmes as they are more likely to be confronted with informational barriers. Paths for future research and implications for policy and practice will be discussed.
\end{abstract}

Keywords: barriers, participation, vocational education, prison

\section{Introduction}

Vocational education in correctional institutions is a growing area of research and policy concern (Spark \& Harris, 2005). Research has shown that participation in vocational education while in prison has several benefits, both for individuals and society, as well as correctional institutions. For instance, prisoners who participate in vocational training programmes have better employment patterns after their release (Lawrence, Mears, Dubin, \& Travis, 2002; Vacca, 2004) and are less involved in disciplinary violations during their imprisonment (Gerber \& Fritsch, 1995). Furthermore, several studies and literature reviews reveal that vocational education is effective in reducing recidivism rates (Gordon \& Weldon, 2003; MacKenzie, 2006; Petersilia, 2003; Wilson, Gallagher, \& MacKenzie, 2000; Ward, 2009).

Along with drawing attention to these positive outcomes, some international literature focuses on the reasons for participation in vocational education. An important motivation is employment-related: e.g., the hope to obtain job qualifications and effectively reintegrate in society (Alós, Esteban, Jódar, \& Miguélez, 2015; Hunter \& Boyce, 2009). Non-employment motivations concern, for example, protecting psychological health, entering into a human interaction with the teacher (Spark \& Harris, 2005), structuring the day, withdrawing from tensions between other prisoners (Hunter \& Boyce, 2009), and distraction from drugs and childcare responsibilities (O'Keeffe, Senior, \& Monti-Holland, 2007).

Conversely, studies on barriers that impede prisoners' participation in vocational training programmes are almost non-existent. A literature review about the motivations and barriers to participation in prison programmes conducted by Brosens (2013) demonstrates that only 2 articles out of 22 focus on the barriers to participation in vocational education (i.e., Alós, Esteban, Jódar, \& Miguélez, 2011; Spark \& Harris, 2005). Furthermore, limited research demonstrates that different variables have an influence on the participation of prisoners in vocational education. For instance, female prisoners are more likely to participate in vocational education compared to their male counterparts, as well as prisoners over 30 years of age (Batiuk, Lahm, Mckeever, Wilcox, \& Wilcox, 2005). Having insight into the profile of those who take part in vocational education is undeniably an important resource. However, research on the aspects that create barriers to prisoners' participation in vocational education is scarce. In response to these research gaps, this article aims to identify potential barriers to vocational education in prison and to examine whether individual, social network and prison-related characteristics are related to the experience of different kinds of barriers. Because the literature on barriers to participation in vocational training programmes is rather scarce (Brosens, 2013), 
this article starts with a discussion of the literature on the barriers that people experience when considering participation in adult education outside prison (e.g., Cross, 1981; Darkenwald \& Merriam, 1982; Flynn, Brown, Johnson, \& Rodger, 2011; Johnstone \& Rivera, 1965). Afterwards, this framework is used to present the available literature on barriers to participation in vocational education while in prison.

\section{Barriers to participation in adult education outside prison}

Several researchers have investigated the barriers to participation in adult education in the general population (Cross, 1981; Darkenwald \& Merriam, 1982; Flynn et al., 2011; Johnstone \& Rivera, 1965). The first study on the reasons for non-participation was conducted by Johnstone and Rivera (1965), who divided the reasons into two categories: internal and external barriers. The internal barriers are grounded in the person's attitude towards learning (dispositional factors), while the external barriers go beyond the individual's situation or control (situational barriers). Dispositional barriers are sometimes called psychosocial barriers, referring to individual beliefs, values, and attitudes that obstruct participation in organised learning activities. Examples are lack of interest, feeling too old to learn, being tired of school, and not enjoying studying (Darkenwald \& Merriam, 1982). Dispositional barriers are also called motivational hindrances (Flynn et al., 2011) or attitudinal barriers (Darkenwald \& Merriam, 1982). Situational barriers are unique to an individual and are usually beyond the control of the educational institution (Bunyan \& Jordan, 2005; Hardin, 2008). A lack of financial support to enrol in an educational course (Hardin, 2008; Johnstone \& Rivera, 1965) and family or time commitments (Cross, 1981) are examples of situational barriers.

Cross (1981) builds further on this framework and adds institutional barriers as part of external barriers, indicating that some adults are excluded from participating in educational activities due to practices and procedures linked to the institution and the educational programmes itself (Flynn et al., 2011). The institutional barriers are divided into five categories: (1) scheduling problems, (2) problems with location or transportation, (3) lack of interesting, practical or relevant courses, (4) procedural problems and time requirements, (5) and lack of information about the programmes and procedures (Cross, 1981). Darkenwald \& Merriam (1982), however, consider the latter, informational barriers, as a distinct category because informational barriers are more than a failure in communicating information about the learning opportunities. It also involves the failure of adults to seek and use the available information.

Limited research has investigated the various characteristics that influence how the different kinds of barriers are experienced. Younger adults and women experience more situational barriers (Johnstone \& Rivera, 1965), while older adults report more dispositional barriers (Johnstone \& Rivera, 1965; Rubenson \& Desjardins, 2009). Regarding socioeconomic status, adults with a low socio-economic status experience more situational barriers (Johnstone \& Rivera, 1965), whereas adults with a higher socio-economic status more frequently experience dispositional barriers (Johnstone \& Rivera, 1965; Rubenson \& Desjardins, 2009). Unfortunately, no research papers were found which address the characteristics that influence institutional and/or informational barriers.

\section{Barriers to participation in vocational training in prison}

Previous studies have applied the above-described framework to present the literature on barriers that people experience when considering participation in different forms of education (e.g., higher education - Hardin, 2008; education programmes designed for older people - Bunyan \& Jordan, 2005; distance learning - Tello, 2007). Although vocational training programmes in prison can be considered a specific form of education (Batiuk et al., 2005; Gordon \& Weldon, 2003; Vacca, 2004), this barrier-framework has not yet been applied to vocational training in prison.

There are only limited numbers of scholars who pay attention to the barriers to participation in vocational training that prisoners experience, and if they do so, mainly institutional barriers are examined. Examples are a lack of available staff and resources (O'Keeffe et al., 2007), a lack of integration between vocational training and prison work (Callan \& Gardner, 2005; O'Keeffe et al., 2007), long waiting lists and getting no answer to their application (Westrheim \& Manger, 2014). In addition, prisoners can face a lack of information about the available opportunities of vocational education in prison (O'Keeffe et al., 2007; Westrheim \& Manger, 2014).

Situational barriers are also discussed in the literature. Prisoners' uncertainty of being able to complete a course due to transfer to another prison or early release can lead to non-participation (Callan \& Gardner, 2005). Also, being disadvantaged in terms of participation opportunities due to serving a short sentence (Alós et 
al., 2015; O'Keeffe et al., 2007) can be considered an example of a situational barrier. When someone is in prison for a short time, it is difficult to get involved in vocational education and consequently it is unlikely that their mind-set changes, which means that these prisoners may be at greater risk of returning to their previous lifestyle (O'Keeffe et al., 2007). While reviewing the literature on vocational education in prison, research on dispositional barriers was not found.

Research has shown that the prison population varies in terms of gender, age, length of incarceration, etc. and that these factors may influence and differentiate the educational motives of prisoners (Manger, Eikeland, Diseth, Hetland, \& Asbjørnsen, 2010). Unfortunately, we found no studies concerning the influence of these variables on the experience of prisoners' barriers to participation in vocational education.

\section{Aim}

Having examined the literature on barriers to participation in vocational training, evidence has been obtained that the existing research is scarce. In response to this, our study wants to contribute to a deeper understanding of this topic. More information about the available forms of vocational education can be found in the description of the measures. However, as our research took place within the context of a remand prison where most of the people await trial, the forms of vocational training were limited. For instance, there were no professionally oriented courses like brick laying, painting or cooking. Consequently, we will use the expression 'vocational orientation programmes' instead of 'vocational education' throughout the article.

The aim of the study is threefold. First, it investigates which types of barriers hinder prisoners' participation in vocational orientation programmes. Second, different types of non-participants are described based on the overriding importance of the different kinds of barriers. Third, research on barriers to participation in adult education has shown that there are differences in the types of barriers to persons in a different life cycle or social position (e.g., age, gender, socio-economic position - Johnstone \& Rivera, 1965). However, to our knowledge, this has never been investigated for vocational education in prison. As such this study aims to investigate which variables predict the experience of the different types of barriers. Consequently, this study seeks to answer three research questions:

(1) What barriers to participation in vocational orientation programmes do prisoners experience?

(2) Which types of non-participants can be distinguished based on the different kinds of barriers?
(3) On which factors (i.e., individual, social network and prison-related features) do the different types of nonparticipants differ from participants of vocational orientation programmes?

\section{Participants}

\section{Methodology}

The research took place in one remand prison in Flanders (Belgium). The goal was to question the whole prison population $(\mathrm{N}=677)$, however 20 prisoners were not able to participate (e.g., being under a special security regime, staying in the hospital, being in the isolation cell, having the status of semi-liberty). Among the 657 prisoners who were able to take part, 486 volunteered to participate in the study, which represents a response rate of $73.9 \%$.

The majority of the respondents were male $(88.9 \%)$, which reflects more or less the make up of the prison population in the prison of Antwerp. In 2012 (when the data collection took place), $91.6 \%$ of the prisoners were male, while $8.4 \%$ were female prisoners. The percentage of female prisoners in the prison of Antwerp is higher compared to the national average. On a national level, $4 \%$ of the prisoners were female and they are spread over 7 correctional institutions (FOD Justice, 2013). Prisoners were aged between 18 and 67 years and the mean age was 33 years $(S D=10.50) .39 .6 \%$ had the Belgian nationality, $28.9 \%$ had another European nationality and $31.5 \%$ a non-European nationality. Half of the respondents reported they had a good understanding of the Dutch language, $28.0 \%$ a little and $21.9 \%$ not at all. Regarding educational attainment, respondents had completed on average 10.2 years of school (kindergarten excluded) $(S D=3.99)$. Looking at the professional status before imprisonment, $30.7 \%$ had a job, 26.1\% was unemployed, $15.7 \%$ worked outside the labour force, and $6.8 \%$ was disabled or on sick leave. The others $(20.7 \%)$ were on career break, a househusband, retired, taking classes or on maternity leave.

\section{Procedures}

This study is part of a larger research project concerning participation in prison programmes (i.e., vocational orientation programmes, educational courses, sport activities, library, socio-cultural training courses, and mental health care) and the reasons for (non-) participation. The survey was undertaken in October 2012 and about 20 volunteers (e.g., activity organisers and members of the University) assisted with the data collection. The questionnaire was administered by selfadministration or face-to-face interviews (in the case of 
less literate prisoners) in a classroom. Because of the great amount of foreign nationals in Belgian prisons (Snacken, 2007), it was important to anticipate possible language barriers (Slotboom, Kruttschnitt, Bijleveld, \& Menting, 2011). Therefore, the questionnaire was made available in 13 languages: Albanian, Arabic, Dutch, English, Farsi, French, German, Italian, Polish, Romanian, Russian, Spanish, and Turkish.

The study was approved by the Ethical Committee of the University. Participation was voluntary and without financial compensation. More information about the methodology of this study can be traced in Brosens, De Donder, Dury \& Verté (2015).

\section{Measures}

Independent variables. To study the different types of (non-) participants, we include individual, social network and prison related features. The five individual characteristics are gender $(0=$ male, $1=$ female $)$, age (measured in years), nationality $(1=$ Belgian, $2=$ other nationality), school attainment (measured in numbers of school years without kindergarten) and understanding of Dutch ( 1 = very good, 2 = a little bit/ not at all). Two social network features are included: having children $(0=$ no, $1=$ yes $)$ and receiving visitors $(0=$ rarely or never, $1=$ at least once a month). In addition, two prison-related features are incorporated: actual length of confinement (the entire sample ranged from less than one week to more than six months with a mean of 4.49 indicating that the majority is in prison between two and three months), and whether someone is a repeat offender $(0=$ no, $1=$ yes $)$.

Dependent variables. Participants were asked if they had participated in vocational orientation programmes. Two forms of vocational orientation programmes were available. First, prisoners could have individual conversations with a consultant who could help them in their search for work, orientate them to vocational training when they are released, give information about vacancies, etc. Additionally, prisoners could follow a vocational training course in a group. During this course the job market was explored, prisoners learned to build up a $\mathrm{CV}$, received solicitation tips and orientation and assessment training were done. Having one conversation with a consultant or following one course was enough to be included in the participant group. As there were no professionally oriented courses available in this remand prison (e.g., painting, cooking, brick laying), we use the term 'vocational orientation programmes' instead of 'vocational education'.

Second, respondents who did not participate in vocational orientation programmes were shown 20 different reasons for non-participation and each respondent was asked to indicate which reasons applied to their own situation (see table 1). These reasons were based on a systematic literature review and preliminary qualitative research (i.e., 6 focus group interviews with professionals of vocational education and prisoners about the motivations and barriers to participation). Afterwards, the barriers were grouped into different categories, based on the literature on barriers to participation in adult educational courses outside prison. We distinguish the 'traditional' types of barriers: situational, dispositional and institutional (e.g., Cross, 1981; Darkenwald \& Merriam, 1982). Similar to Darkenwald \& Merriam (1982) we also consider the informational barriers as a separate category. Further, some items were added to the questionnaire because they were indicated during the focus group interviews, and two extra categories of barriers were formed with these items. The fifth category of barriers is the possible clash between different activities and participation in vocational orientation programmes. A last category, which is not mentioned in previous studies, is "having no need to take part". These prisoners possibly do not see a purpose or reason for participating (Desjardins, Rubenson, \& Milana, 2006) as, for example, they might already have a job when released. Ultimately, we combined the different kinds of barriers with the participation variable and got a new variable with seven categories: (1) non-participants having no need to get engaged, (2) non-participants experiencing institutional barriers, (3) non-participants facing informational barriers, (4) non-participants experiencing dispositional barriers, (5) non-participants having preferences for other activities, (6) non-participants facing situational barriers, and (7) participants of vocational orientation programmes. Belonging to the first category of nonparticipants (i.e., having no need for vocational orientation programmes) does not mean that these prisoners do not experience other kinds of barriers, but first of all it is necessary that someone is in need of vocational orientation programmes to get engaged. This applies to all the other categories. For instance, prisoners who express informational barriers do not face institutional barriers, but it is possible that they also experience situational barriers. The hierarchical division of the different types of non-participants is based on group conversations with professionals to increase face validity.

\section{Data analyses}

Data was analysed using SPSS 22.0. First, the frequencies of the different barriers and their division 
into several categories are displayed. Second, bivariate analyses are conducted to see whether the different types of non-participants and participants of vocational orientation programmes differ on individual, social network and prison-related features. Chi-square tests are used for categorical variables and for variables showing statistically significant differences at a level of $\mathrm{p} \leq .05$, Z-tests or column proportion tests are used to determine which categories were causing the difference. For the continuous variables, one-way ANOVA and Bonferroni post-hoc tests are performed. Third, multinomial logistic regression analyses are conducted to measure the differences between participants of vocational orientation programmes and the different types of non-participants. Only the variables that are significantly related in the bivariate analyses are included in the regression. We controlled for multicollinearity among these variables by calculating the tolerance and variance inflation factors. The significance level was set at $\mathrm{p} \leq .05$ and odds ratios are presented to indicate the size of the effects.

\section{Results}

First of all, the respondents were asked if they have participated in vocational orientation programmes. $42.1 \%$ of the respondents had at least one conversation with a consultant of the employment service or followed a vocational training course. $57.9 \%$ did not participate in vocational orientation programmes.

\section{Types of barriers to participation to vocational orientation programmes}

The respondents who did not participate in vocational orientation programmes were asked to indicate which reasons for non-engagement applied to their own situation (see table 1).

Prisoners are mostly confronted with situational $(48.7 \%)$ or informational barriers $(46.1 \%)$. The majority of prisoners who report situational barriers are hindered in their attempts to participate in vocational training programmes because they only recently arrived in prison, which is the second most indicated barrier in general. The most frequently cited reason for non-participation refers to the informational category of barriers: being unaware of the possibility to follow vocational education (42.1\%). In addition, about 1 in 4 prisoners indicate having preferences for other activities. The most decisive reason for non-participation in this category is having preferences to go to work. Not being in need of vocational training is also indicated by 1 in 4 of the non-participants. Having a job at the time of release from prison in particular is a decisive factor.
$13.9 \%$ indicated at least one institutional barrier and the most mentioned barriers are having received no answer to a report note (i.e., their request to register) and having no courses. Finally, dispositional barriers are the least mentioned category $(4.3 \%)$.

\section{Types of non-participants}

Ranked on hierarchal importance of the barriers, a classification of different types of non-participants is developed (see table 2).

Non-participants of group 1 have a need for vocational orientation programmes, but are confronted with situational barriers that hinder their participation $(9.6 \%)$. Group 2 contains prisoners who are also in need of vocational orientation programmes, but the timing of vocational programmes clash with other activities; they have a preference for going to work, receiving visitors, going out for fresh air, etc. Prisoners have to choose between following vocational orientation programmes and doing one of these other activities $(6.9 \%)$. For the prisoners belonging to group 3 of non-participants, personal barriers (e.g., do not feel like it) hinder their participation $(1.2 \%)$. It is essential that prisoners have enough information about participation opportunities. $18.2 \%$ are faced with a lack of information (group 4). Group 5 contains prisoners who are in need of vocational orientation programmes, but when someone is in need, it is essential that there is an appropriate offer. 5.9\% of the respondents find that it falls short here. Group 6 of non-participants are prisoners who have no need to follow vocational orientation programmes. Some of them already have a job when they will be released, do not intend to stay in Belgium or are no longer allowed to work due to illness or disability. In total, $16.0 \%$ of all the respondents belong to this category.

\section{Bivariate analysis: Factors influencing the experience of the different types of barriers}

Table 3 shows that Belgian prisoners and those with a good understanding of the Dutch language more frequently participate in vocational orientation programmes. Prisoners with another nationality and who do not master the Dutch language sufficiently more frequently report experiencing institutional and informational barriers that hinder their participation. Prisoners facing dispositional barriers have longer school careers than those who experience institutional barriers or prisoners who are not in need of vocational orientation programmes. There is also a tendency that prisoners with shorter school careers lack more frequently information about the participation opportunities than those facing dispositional barriers. 
Table 1.

Barriers to participation in vocational orientation programmes $(n=230)$

\begin{tabular}{|c|c|c|}
\hline & Barriers & $\%$ \\
\hline \multirow[t]{4}{*}{ Situationalbarriers } & Thave only just arrived in prison & 36.1 \\
\hline & I do not know when I will be released & 18.3 \\
\hline & I cannot take training because I have not been convicted & 6.5 \\
\hline & Subtotal & 48.7 \\
\hline \multirow[t]{3}{*}{ Informational barriers } & I was not aware of the possibility & 42.2 \\
\hline & I do not know how to sign up & 17.4 \\
\hline & Subtotal & 46.1 \\
\hline \multirow[t]{6}{*}{ Having other preferences } & I prefer to go to work & 19.1 \\
\hline & I prefer to go see my visitors & 7.0 \\
\hline & I prefer to go outside for fresh air & 6.1 \\
\hline & I prefer to attend my religious service & 4.8 \\
\hline & I prefer to do something else & 3.5 \\
\hline & Subtotal & 26.1 \\
\hline \multirow[t]{5}{*}{ Being not in need } & I already have a job when I am on the outside & 16.1 \\
\hline & I do not intend to stay in Belgium & 8.7 \\
\hline & I am no longer allowed to work due to illness or disability & 3.0 \\
\hline & I do not want to work & 0.4 \\
\hline & Subtotal & 26.1 \\
\hline \multirow[t]{5}{*}{ Institutional barriers } & I requested to enrol, but I never received an answer & 7.0 \\
\hline & There were no courses & 5.2 \\
\hline & The subjects of the courses are not interesting & 1.7 \\
\hline & I wanted to, but the courses were fully booked & 1.3 \\
\hline & Subtotal & 13.9 \\
\hline \multirow[t]{2}{*}{ Dispositional barriers } & I do not feel like it & 3.0 \\
\hline & $\begin{array}{l}\text { I am too tired to participate } \\
\text { Subtotal }\end{array}$ & $\begin{array}{l}1.3 \\
4.3\end{array}$ \\
\hline
\end{tabular}

Concerning social network features, prisoners who receive visitors on a regular basis take more part in vocational training programmes. Those who rarely or never receive visitors are more frequently not in need to taking part, or they experience informational barriers. Prisoners with children are more frequently confronted with institutional barriers, and those without children report more often having a lack of information about the participation opportunities.

Finally, different prison-related characteristics are also related to participation. Repeated offenders are more frequently involved in vocational training than first-time offenders. Prisoners experiencing situational barriers are in prison for a shorter time compared to both participants as well as the other groups of non- participants.

There are no significant differences in terms of age and gender. Consequently, these are excluded from the logistic regression.

Logistic regression analyses: Factors influencing the differences between participants and different types of non-participants

Table 4 contains the results of the multinomial logistic regression analyses. Participants of vocational orientation programmes are compared with the different types of non-participants, based on different individual, social network and prison-related features. For instance, the individual characteristics (e.g., age, gender, ethnicity) that make prisoners more likely to 
Table 2.

Types of participants and non-participants of vocational orientation programmes $(n=406)$

\begin{tabular}{|c|c|c|c|c|c|c|c|c|}
\hline & $\begin{array}{l}\text { Is the } \\
\text { prisoner } \\
\text { in need to } \\
\text { follow vo- } \\
\text { cational } \\
\text { training? }\end{array}$ & $\begin{array}{l}\text { Does the } \\
\text { prisoner } \\
\text { experience } \\
\text { institution- } \\
\text { al barri- } \\
\text { ers? }\end{array}$ & $\begin{array}{l}\text { Does the } \\
\text { prisoner } \\
\text { lack infor- } \\
\text { mation? }\end{array}$ & $\begin{array}{l}\text { Does the } \\
\text { prisoner } \\
\text { experi- } \\
\text { ence dis- } \\
\text { positional } \\
\text { barriers? }\end{array}$ & $\begin{array}{l}\text { Does the } \\
\text { prisoner } \\
\text { prefer } \\
\text { other ac- } \\
\text { tivities? }\end{array}$ & $\begin{array}{l}\text { Does the } \\
\text { prisoner } \\
\text { experi- } \\
\text { ence sit- } \\
\text { uational } \\
\text { barriers? }\end{array}$ & $\begin{array}{l}\text { Does the } \\
\text { prisoner } \\
\text { take part? }\end{array}$ & $\%$ \\
\hline Participants & Yes & No & No & No & No & No & Yes & 42.1 \\
\hline NP group 1 & Yes & No & No & No & No & Yes & No & 9.6 \\
\hline NP group 2 & Yes & No & No & No & Yes & I & No & 6.9 \\
\hline NP group 3 & Yes & No & No & Yes & I & I & No & 1.2 \\
\hline NP group 4 & Yes & No & Yes & I & l & l & No & 18.2 \\
\hline NP group 5 & Yes & Yes & I & I & I & l & No & 5.9 \\
\hline NP group 6 & No & I & I & I & I & I & No & 16.0 \\
\hline
\end{tabular}

experience certain barriers to participation in vocational orientation programmes are investigated.

The regressions examine the effect of different predictors between the various types of non-participants and participants of vocational orientation programmes. Prisoners with children and those who never or rarely received visitors were about 2.5 times more likely to not be in need of vocational orientation programmes than to be a participant (respectively $\mathrm{OR}=2.318$; OR $=2.739, p<.05)$. First-time offenders were also more likely to have no need for vocational training than to participate $(\mathrm{OR}=1.875, \mathrm{p}<.10)$.

When comparing participants and non-participants experiencing institutional barriers (group 2), prisoners with a poor understanding of the Dutch language and those with children were more likely to face this kind of barrier than to be a participant of vocational orientation programmes (respectively $\mathrm{OR}=4.392 ; \mathrm{OR}=2.915$, $\mathrm{p}$ $<.10)$.

Prisoners with a poor or little understanding of the Dutch language $(\mathrm{OR}=4.724, \mathrm{p}<.05)$, first time offenders, $(\mathrm{OR}=2.520, \mathrm{p}<.05)$, those with a foreign nationality $(\mathrm{OR}=2.493, \mathrm{p}<.10)$, and those who never or rarely received visitors $(\mathrm{OR}=2.289, \mathrm{p}<.10)$ were more likely to face informational barriers than to participate in vocational orientation programmes. Besides, time of confinement is negatively related to experiencing informational barriers. Prisoners with a longer current sentence length were $20 \%$ less likely to be non-participants due to informational barriers (OR $=.797, \mathrm{p}<.05)$ than to be participants in vocational training programmes.

Having other preferences is associated with whether or not someone was a first time prisoner and understand- ing of the Dutch language. First time offenders $(\mathrm{OR}=3.268, \mathrm{p}<.05)$ and those with a poor or little understanding of the Dutch language $(\mathrm{OR}=3.169, \mathrm{p}<$ .10) were three times more likely to have preferences for other activities than to be a participant in vocational orientation programmes.

Lastly, those with a short current sentence length $(\mathrm{OR}=.422, \mathrm{p}<.05)$, a higher number of school years attended $(\mathrm{OR}=1.156, \mathrm{p}<.05)$, with children $(\mathrm{OR}=$ $2.419, \mathrm{p}<.10)$ and a poor or little understanding of the Dutch language $(\mathrm{OR}=3.203, \mathrm{p}<.10)$ were more likely to be confronted with situational barriers than to participate in vocational training.

This model explained between $41.0 \%$ and $42.9 \%$ of the variance between the different types of nonparticipants and participants of vocational education.

\section{Discussion}

Our study is one of the first that investigates the barriers that hinder the participation of prisoners in vocational orientation programmes. The framework of factors that impede participation in adult education outside prison (e.g., Cross, 1981; Darkenwald \& Merriam, 1982; Johnstone \& Rivera, 1965) is applied to vocational education in prison. Furthermore, the framework is extended by the introduction of clashing activities and a lack of need to get involved in vocational education. When considering the different types of barriers independently, it is demonstrated that prisoners who do not take part in vocational orientation programmes while in prison are in particular confronted with situational and informational barriers. To some extent, prisoners also have preferences for other activities or are not in need of vocational education. Experiencing 


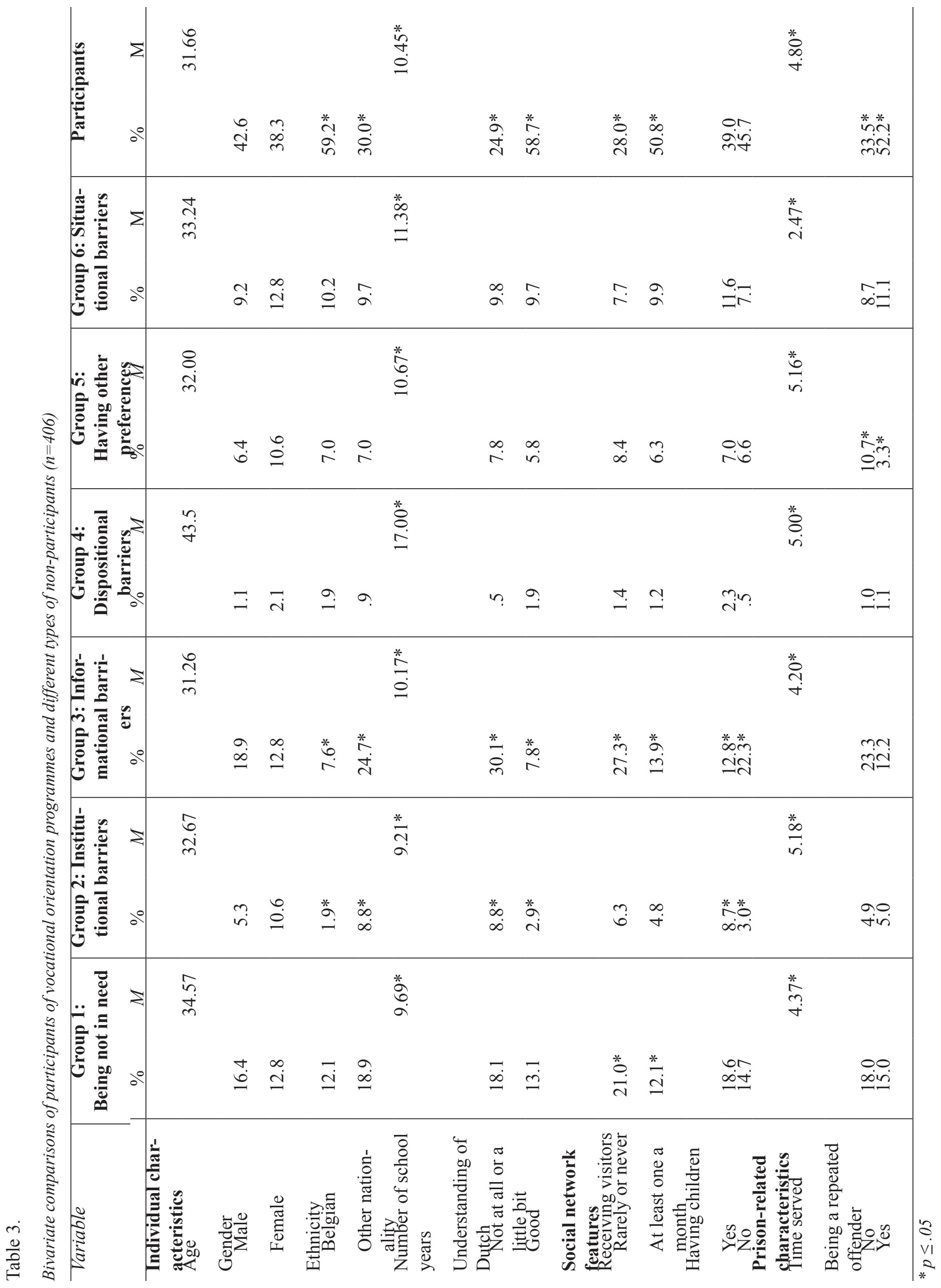




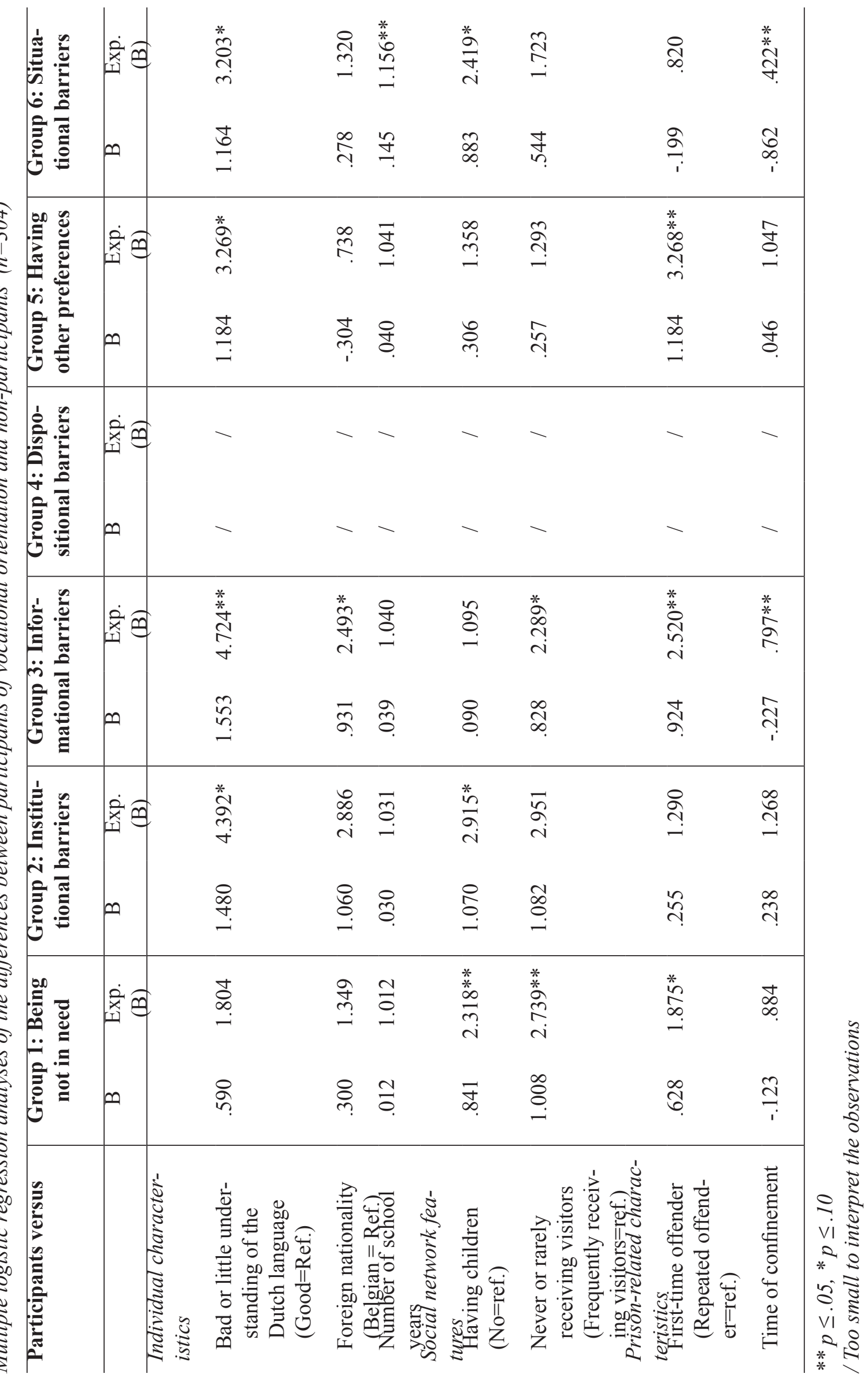


institutional barriers, and in particular dispositional barriers, is less common.

The different types of non-participants are compared with participants of vocational orientation programmes on individual, social network and prison-related features using multinomial logistic regression analysis. The results show that knowledge of the Dutch language (an individual characteristic) is the most powerful factor in explaining the differences between those experiencing informational barriers and participants of vocational orientation programmes. Previous research has shown that language barriers prevent foreign prisoners' equitable participation in prison activities (Atabay, 2009). A lack of information about the educational opportunities in a language they understand impedes the participation possibilities of this group (Westrheim \& Manger, 2014). Our research strengthens these findings. It is knowledge of a particular language, and not nationality, that determines the possibility of understanding the information about the participation opportunities. Accordingly, nationality and language understanding should not be considered as synonyms. There are Belgian prisoners who experience language difficulties and foreign prisoners who master the Dutch language sufficiently.

A second individual characteristic that explains the differences between participants and non-participants of vocational orientation programmes is the number of years of schooling. The longer prisoners have been to school, the more often situational barriers are experienced. This is in contrast with research concerning participation in adult education in 'free' society which states that low-educated people are more likely to experience these kinds of barriers (e.g., Johnstone \& Rivera, 1965; Rubenson \& Desjardins, 2009). However, it is not possible to compare the groups of people who experience situational barriers inside and outside prison, as the experienced barriers are completely different. For instance, possible situational barriers that people outside prison experience are a lack of financial support (Hardin, 2008; Johnstone \& Rivera, 1965) and family or time commitments (Cross, 1981). A possible explanation for why prisoners with a longer school career identify situational barriers more frequently may be that these people want to have certainty about their detention situation before they start participating in vocational orientation programmes. Future research is recommended to identify the reasons why these prisoners more frequently face situational barriers to participation in vocational orientation programmes.

Also, social network features are related with whether prisoners take part in vocational orientation programmes. Prisoners with children express more frequently a lack of need for vocational orientation programmes than the desire to be a participant. This is surprising, as the literature about participation in (vocational) educational courses while in prison has shown that parents are motivated to participate because they want to be a decent role model for their children (e.g., Hall \& Killacky, 2008; Schlesinger, 2005; Torre \& Fine, 2005). However, incarceration inevitably disrupts family relations and not all imprisoned parents have the possibility to have or maintain contact with their children (Vigne, Naser, Brooks, \& Castro, 2005). Furthermore, the majority of parents worry about their children while they are in prison (Bahr, 2007). It may be possible that these worries hinder prisoners from participating in vocational orientation programmes. Additional research could provide more insight into this issue.

In addition, previous research has shown that prisoners who receive visitors are more likely to participate in educational courses than those who do not receive visitors (Rose, 2004). This is in line with our results. Visitation is considered important, as it allows prisoners to receive social support and maintain connections to the outside world (Connor \& Tewksbury, 2015). A plausible explanation might be that the people who come to visit prisoners motivate them to take part in vocational education.

Finally, prison-related features also have an influence on the experience of various kinds of barriers. First time offenders and those with a short current sentence length are more likely to face informational hindrances than to be a participant. Previous research has shown that prisoners can face a lack of information about the available opportunities of vocational education in prison (O'Keeffe et al., 2007; Westrheim \& Manger, 2014). It is possible that as time passes, prisoners become more aware of the possibilities for following vocational education, and that prisoners with various prison experiences are informed about the offer due to their previous stay. To anticipate this, certain prisons in the United Kingdom employ prisoners as 'insiders' to provide information about prison life, in particular to newcomers and first-time prisoners (Edgar, Jacobson, \& Biggar, 2011; Jaffe, 2012). Besides, time served seems in particular to have an influence on the experience of situational barriers. Prisoners with a short current sentence length are more likely to face situational barriers than to be a participant. This is a logical conclusion because most of the situational barriers are related to the beginning of a prison sentence (i.e., being just arrived in prison, not knowing their release date, 
and not having been convicted yet).

A last prison-related difference is found between prisoners who have preferences for other activities and participants of vocational orientation programmes. First time prisoners are more likely to prefer to do something else (e.g., going to work, receiving visitors, going outside for fresh air). Previous research has shown that there is a lack of integration between vocational training and prison work (Callan \& Gardner, 2005; O'Keeffe et al., 2007). However, the reason that having other preferences is indicated more by first time offenders remains unclear. Further research is recommended to investigate this more in depth in order to provide an explanation.

\section{Limitations}

There are some limitations that might affect the interpretation of the results presented. Because the study took place in one remand prison in Belgium, it is not possible to generalize the findings to other prisons. Previous research has shown that characteristics that are specific to one prison (e.g., security level, crowding) can have an influence on the behaviour of prisoners (Dye, 2010; Lahm, 2008). Including both correctional institutions with remanded prisoners and prisons where sentences are served would enrich the data and could indicate the similarities and differences in the experience of barriers to participation in vocational education among various prison populations. For instance, this research shows that situational barriers are the most identified category of barriers. We hypothesize that these barriers are of less importance in prisons holding only convicted prisoners.

Second, the forms of vocational training in this study are limited because of the context of a remand prison. Prisoners can only have conversations with a consultant or follow some courses in a group (e.g., learning to build up a $\mathrm{CV}$, getting solicitation tips, orientation and assessment trainings). It would be interesting to investigate the barriers that prisoners face to participation in a greater variety of vocational programmes, for instance professionally oriented courses (e.g., brick laying, painting, kitchen and cooking). Mostly, these courses are offered in correctional institutions where sentences are served. Nevertheless, more than research attention for participation in vocational education is necessary. The study of barriers to prison education more generally should be an important area for future research. Most of the research about prison education focuses on the motivations to take part (e.g., Boshier, 1983; Maggioncalda, 2007; Manger et al., 2010), while existing research on the barriers is rather scarce
(Brosens, 2013).

Besides, our study has shown that $42.1 \%$ of the prisoners have participated at least once in vocational orientation programmes. Nevertheless, we do not know if they experienced certain categories of barriers in the past. It can be that they were confronted with, for instance, situational or institutional barriers, but that they overcame these difficulties or participated despite certain barriers they experienced. Future research can provide more insight into these aspects.

-Furthermore, due to the low educational level of the prisoners (Behan, 2014; Social Exclusion Unit, 2002), it was necessary to develop an accessible and user-friendly questionnaire. In order to so, first specialists on clear language usage checked the survey instrument. Afterwards, the questionnaire was piloted among 34 prisoners. During and after the prisoners had completed the survey, they were asked to reflect on the user-friendliness and the content of the questionnaire. We had the intention of including various validated measurement instruments in the final questionnaire (e.g., GHQ-12, MOS-scale). During the pilot phase, the prisoners were asked to fill in the GHQ-12 as a test. It became clear that it was very difficult for them to fill in these kinds of questions. Ultimately, we decided not to include more validated measurement instruments in the final questionnaire. Also questions about the barriers could be presented using likert scales so that the respondents could indicate how important a barrier was in comparison with other barriers. However, due to their low educational level, we decided to use nominal categorical variables (yes/no) in the questions about barriers due to their simplicity.

A fourth limitation is linked to the number of dispositional barriers included in our study, which is rather small. The number of dispositional barriers could be increased by the inclusion of barriers indicated in the literature about participation in adult education in the general population, e.g., feeling too old to learn or not enjoying participation in vocational education (Darkenwald \& Merriam, 1982).

\section{Implications for policy and practice and future research}

Despite the limitations, this study provides innovative insights into the barriers that hinder prisoners' participation in vocational orientation programmes. Having insights into these aspects, policy makers and activity organisers can try to anticipate the barriers and strive to make the offer available for everyone who wants to take part in vocational orientation programmes. Because barriers on various levels 
determine non-participation, we discuss separately the possible interventions at each level.

First, it seems easiest to anticipate informational barriers. In particular, prisoners who have difficulties with the Dutch language do not take part in vocational training because they experience a lack of information about the participation opportunities. Policy makers and activity organisers can inform prisoners facing language barriers about the offer of Dutch language courses. Such courses can help prisoners to understand the information that is given and their surrounding in the prison (Westrheim \&, 2013). It is necessary that the education opportunities are pointed out and that information is given about how to apply (West, 1994). For foreign prisoners it is essential that information is given in an understandable language (Westrheim \& Manger, 2014). Besides, cooperation between the educational providers responsible for the Dutch language courses and vocational training would be interesting. One possibility might be to use a vocational training course as an applied Dutch course. Furthermore, first time prisoners and those who are recently arrived in prison also frequently indicate informational barriers. Special attention might be paid to these groups in disseminating information about the offer of vocational training.

Another category of barriers that seems possible to anticipate is the perceived lack of need. Our study demonstrates that prisoners who rarely or never receive visitors are more likely to have no need to take part in vocational education. It is possible that community volunteers could play a valuable role for these prisoners, as in some cases visitation from family and friends might be challenging (e.g., sex offenders, foreign nationals). Visiting volunteers can be useful for providing these prisoners with social support and connections to the outside world (Connor \& Tewksbury, 2015). Although having visits from community volunteers might be less effective in affecting prisoners' behaviour than visits of close relatives, the interactions with these volunteers can help prisoners to offset the day-to-day strains of prison life (Cochran \& Mears, 2013) and might provide them with valuable information about prison opportunities.

Third, anticipating institutional barriers also seems to be possible. Receiving no answer to a report note (i.e., request to register) and lack of course availability are the most indicated hindrances within this category. Additional research could reveal the reasons why activity organisers do not always respond to the report notes and which vocational training courses prisoners want to follow.
Furthermore, having preferences for other activities like going to work, receiving visitors and going outside for fresh air also prevents some prisoners from taking part. A prison wherein the different activities take place at different times could tackle these barriers. In this kind of prison, people can work during the day and follow vocational training during the evening, for instance. In particular first time offenders express having preferences for other activities. Research could shed additional light on the reasons why this group more frequently wants to do something other than take part in vocational education.

There is also a group of prisoners who do not participate due to dispositional barriers. Reducing these hindrances concerns encouragement, motivation and emotional support (Sticht, McDonald, \& Erickson, 1998).

Finally, anticipating situational barriers seems to be the most difficult as these barriers are outside the control of the educational providers (Bunyan \& Jordan, 2005). Most of these barriers are related to the beginning of a prison sentence. We would recommend anticipating other kinds of obstacles. Previous research outside correctional institutions has also indicated that it is difficult to make recommendations for tackling situational barriers (Sticht et al., 1998).

\section{References}

Alós, R., Estaban, F., Jódar, P., \& Miguélez, F. (2011). Effects of prison work programmes on the employability of ex-prisoners. (DemoSoc Working Paper No. No. 2011-43). Barcelona: Universitat Pompeu Fabra.

Alós, R., Esteban, F., Jódar, P., \& Miguélez, F. (2015). Effects of prison work programmes on the employability of ex-prisoners. European Journal of Criminology, 12(1), 35-50, doi: $10.1177 / 1477370814538776$.

Atabay, T. (2009). Handbook on prisoners with special needs. Criminal justice handbook series. Vienna: United Nations Publications.

Bahr, S. J. (2007). Incarceration, poverty, and families. In D. R. Crane \& T. B. Heaton (Eds.), Handbook of Families and Poverty (pp. 269-287). California: Sage Publications.

Batiuk, M. E., Lahm, K. F., Mckeever, M., Wilcox, N., \& Wilcox, P. (2005). Disentangling the effects of correctional education: Are current policies misguided? An event history analysis. Criminal Justice, 5(1), 55-74, doi: 10.1177/1466802505050979.

Behan, C. (2014). Learning to escape: Prison education, rehabilitation and the potential for transformation. 
Journal of Prison Education and Reentry, 1(1), 20 31, doi: 10.15845/jper.v1i1.

Boshier, R. (1983). Education inside. Motives for participation in prison education programmes. Vancouver: University of British Colombia.

Brosens, D. (2013). Participation in prison programmes: Encouraging and discouraging factors. In P. Ponsaers, A. Crawford, J. de Maillard, J. Shapland, \& A. Verhage (Eds.), Crime, violence, justice and social order. Monitoring contemporary security issues (pp. 257-298). Antwerp: Maklu.

Brosens, D., De Donder, L., Dury, S., \& Verté, D. (2015). Building a research partnership in a prison context: From collaboration to co-construction. Sociological Research Online, 20(3), doi: 10.5153/3693.

Bunyan, K., \& Jordan, A. (2005). Too late for the learning: lessons from older learners. Research in Post-Compulsory Education, 10(2), 267-288.

Callan, V., \& Gardner, J. (2005). Vocational education and training provision and recidivism in Queensland correctional institutions. Adelaide: National Center for Vocational Education Research.

Cochran, J. C., \& Mears, D. P. (2013). Social isolation and inmate behavior: A conceptual framework for theorizing prison visitation and guiding and assessing research. Journal of Criminal Justice, 41(4), 252261, doi: 10.1016/j.jcrimjus.2013.05.001.

Connor, D. P., \& Tewksbury, R. (2015). Prison inmates and their visitors: An examination of inmate characteristics and visitor types. Prison Journal, 95(2), 159-177, doi: 10.1177/0032885515575262.

Cross, K. P. (1981). Adults as learners: Increasing participation and facilitating learning. San Francisco: Jossey-Bass.

Darkenwald, G. G., \& Merriam, S. B. (1982). Adult education: Foundations of practice. Harper \& Row.

Desjardins, R., Rubenson, K., \& Milana, M. (2006). Unequal chances to participate in adult learning: International perspectives. Paris: UNESCO.

Dye, M.H. (2010). Deprivation, importation, and prison suicide: Combined effects of institutional conditions and inmate composition. Journal of Criminal Justice, 38(4), 796-806, doi: 10.1016/j. jcrimjus.2010.05.007.

Edgar, K., Jacobson, J., \& Biggar, K. (2011). Time well spent: A practical guide to active citizenship and volunteering in prison. London: Prison Reform Trust.

Flynn, S., Brown, J., Johnson, A., \& Rodger, S. (2011). Barriers to education for the marginalized adult learner. Alberta Journal of Educational Research, 57(1), 43-58.
FOD Justice (2013). Directorate general Penitentiary: Annual report 2012. Brussels: DG EPIPenitentiaries.

Gerber, J., \& Fritsch, E. J. (1995). Adult academic and vocational correctional education programs: A review of recent research. Journal of Offender Rehabilitation, 22(1-2), 119-142, doi: 10.1300/ J076v22n01_08.

Gordon, H. R. D., \& Weldon, B. (2003). The impact of career and technical education programs on adult offenders: Learning behind bars. Journal of Correctional Education, 54(4), 200-209.

Hall, R. S., \& Killacky, J. (2008). Correctional education from the perspective of the prisoner student. Journal of Correctional Education, 59(4), 301-320.

Hardin, C. J. (2008). Adult students in higher education: A portrait of transitions. New Directions for Higher Education, 2008(144), 49-57, doi: 10.1002/he.325.

Hunter, G., \& Boyce, I. (2009). Preparing for employment: Prisoners' experience of participating in a prison training programme. The Howard Journal of Criminal Justice, 48(2), 117-131, doi: 10.1111/j.1468-2311.2008.00551.x.

Jaffe, M. (2012). Peer support and seeking help in prison: A study of the Listener scheme in four prisons in England (Doctoral dissertation). Keele University, Keele.

Johnstone, J. W. C., \& Rivera, R. J. (1965). Volunteers for learning: A study of the educational pursuits of American adults. Aldine Publishing Company.

Lahm, K. F. (2008). Inmate-on-inmate assault: A multilevel examination of prison violence. Criminal Justice and Behavior, 35(1), 120-137, doi: 10.1177/0093854807308730.

Lawrence, S., Mears, D. P., Dubin, G., \& Travis, J. (2002). The practice and promise of prison programming. Washington, D.C.: Urban Institute: Justice Policy Center.

MacKenzie, D. L. (2006). What works in corrections: Reducing the criminal activities of offenders and delinquents. Cambridge: Cambridge University Press.

Maggioncalda, E.C. (2007). Inmate motivations to participate in prison programs: Are they related to actual participation? (Doctoral dissertation). Capella University.

Manger, T., Eikeland, O., Diseth, Å., Hetland, H., \& Asbjørnsen, A. (2010). Prison inmates' educational motives: Are they pushed or pulled? Scandinavian Journal of Educational Research, 54(6), 535-547, doi: 10.1080/00313831.2010.522844.

O'Keeffe, C., Senior, P., \& Monti-Holland, V. (2007). 
Barriers to employment, training and education in prison and beyond: A peer-led solution. In R. Sheehan, G. McIvor, \& C. Trotter (Eds.), What works with women offenders (pp. 240-261). Portland: Willian Publishing.

Petersilia, J. (2003). When prisoners come home: Parole and prisoner reentry. Oxford University Press.

Rose, C. (2004). Women's participation in prison education: What we know and what we don't know. Journal of Correctional Education, 55(1), 78-100.

Rubenson, K., \& Desjardins, R. (2009). The impact of welfare state regimes on barriers to participation in adult education: A bounded agency model. Adult Education Quarterly, 59(3), 187-207, doi: 10.1177/0741713609331548.

Schlesinger, R. (2005). Better myself: Motivation of African Americans to participate in correctional education. Journal of Correctional Education, 59(4), 339-347.

Slotboom, A.-M., Kruttschnitt, C., Bijleveld, C., \& Menting, B. (2011). Psychological well-being of incarcerated women in the Netherlands: Importation or deprivation? Punishment \& Society, 13(2), 176197, doi: 10.1177/1462474510396313.

Snacken, S. (2007). Penal policy and practice in Belgium. In Crime, Punishment and Politics in Comparative Perspective, 36(3), 127-215.

Social Exclusion Unit. (2002). Reducing re-offending by ex-prisoners. London: Social Exclusion Unit.

Spark, C., \& Harris, A. (2005). Vocation, vocation: A study of prisoner education for women. Journal of Sociology, 41(2), 143-161, doi: 10.1177/1440783305053232.

Sticht, T. G., McDonald, B., \& Erickson, P. R. (1998). Passports to paradise: The struggle to teach and to learn on the margins of adult education. San Diego: San Diego consortium for workforce education and lifelong learning.

Tello, S. F. (2007). An analysis of student persistence in online education. Journal of Information and Communication Technology, 3(3), 47-62.

Torre, M.E., \& Fine, M. (2005). Bar none: Extending affirmative action to higher education in prison. Journal of Social Issues, 61(3), 569-594, doi: 10.1111/j.1540-4560.2005.00421.x.

Vacca, J. S. (2004). Educated prisoners are less likely to return to prison. Journal of Correctional Education, 55(4), 297-305.

Vigne, N. G. L., Naser, R. L., Brooks, L. E., \& Castro, J. L. (2005). Examining the effect of incarceration and in-prison family contact on prisoners' family relationships. Journal of Contemporary Criminal Justice, 21(4), 314-335, doi: 10.1177/1043986205281727.

Ward, S. A. (2009). Career and technical education in United States prisons: What have we learned? Journal of Correctional Education, 60(3), 191-200.

Westrheim, K., \& Manger, T. (2013). Similarities and differences in Nordic countries. In K. Westrheim \& T. Manger (Eds.), Educational background, preferences and needs. A qualitative study of prisoners from Iraq, Poland, Russia, Serbia and Somalia (pp. 157-168). Bergen: County Governor of Hordaland, Department of Education.

Westrheim, K., \& Manger, T. (2014). Iraqi prisoners in Norway: Educational background, participation, preferences and barriers to education. Journal of Prison Education and Reentry, 1(1), 6-19, doi: 10.15845/jper.v1i1.

West, T. (1994). The education of prisoners. In W. Tulasiewicz \& G. Strowbridge (Eds.), Education and the Law. International perspectives (pp. 127137). Routledge: London.

Wilson, D. B., Gallagher, C. A., \& MacKenzie, D. L. (2000). A meta-analysis of corrections-based education, vocation, and work programs for adult offenders. Journal of Research in Crime and Delinquency, 37(4), 347-368, doi: 10.1177/0022427800037004001. 
Dorien Brosens has just finished a PhD about prisoners' participation in correctional programmes (e.g., education, vocational education, sport activities, library). More specifically, she is interested in the profile of (non-)participants and their related motives or barriers.

Liesbeth De Donder is a professor in Adult Educational Sciences and has been involved in several research projects concerning safety, social participation, elder abuse, quality of care and participatory research methodologies.

Sarah Dury has a post-doc fellowship and has just finished a $\mathrm{PhD}$ on volunteering among older people. Her research interests focus on volunteering, civic engagement and the dynamics of social inclusion and exclusion.

Dominique Verté is a Professor in the department of Educational Sciences and is head of the Belgian Ageing Studies research group. He supervises several PhD students in the field of social gerontology and participation. 